\title{
The Role of Microcellular Rubber in the Preservation of Anaesthetic Feet in Leprosy*
}

\author{
Mrs. S. KARAT† \\ Consultant Surgeon \\ Schieffelin Leprosy Research Sanatorium, Karigiri, Via Katpadi, N.A. District, S. India

\begin{abstract}
In this paper the significant aetiological factors in the causation of plantar ulceration and its recurrence, particularly in patients with anaesthetic feet, are first briefly reviewed. Full details are then given for the construction of a type of sandal or chappal embodying a sole of microcellular rubber ("microporous compound") which when properly made and constantly worn gives excellent hope of preventing ulceration or its recurrence.
\end{abstract}

\section{INTRODUCTION}

Plantar ulceration is one of the major causes of disablement among leprosy patients. In the absence of protective footwear plantar ulceration continues to persist or recur with increasing frequency, gradually disabling the patient. The reported prevalence of plantar ulceration based on epidemiological studies have ranged from $15.7 \%$ of the feet examined (Noordeen and Srinivasan, 1966$)$ to $36.41 \%$ of the patient population (Leprosy Centre, Polambakkam). In our own studies in Gudiyatham Taluk, North Arcot District, $17.7 \%$ of the patient population had a history of plantar ulceration (Rao et al.). Since anaesthetic feet is a permanent disability in the majority of these patients, the treatment and management of plantar ulceration need to be considered in terms of long-range care rather than on immediate results. Prevention of plantar ulceration will depend upon our ability to identify the major causes of the initiation and recurrence of ulcers, as well as on our ability to successfully protect the anaesthetic feet by designing a suitable type of footwear. In most developing countries footwear is either not used at all or the conventional closed footwear is impracticable becase of occupational and social considerations. In this paper a few significant aetiological factors in the causation and re-

*Received for publication 30 .June, 1969.

†Senior Lecturer in Surgery, Christian Medical College and Hospital, Vellore-4, N.A. District, S. India. currence of plantar ulceration are described and methods of preventing such ulceration by the use of microcellular rubber footwear is discussed.

\section{PLANTAR ULCERATION \\ Causes of initiation of plantar ulceration}

Plantar ulceration may be initiated by accidental trauma such as a thorn or nail prick. Its inability to appreciate pain makes the anaesthetic foot much more liable to such injuries during normal walking. The ulceration may also occur as a complication of the deep fissures that are frequently seen in unprotected, anaesthetic and anhydrotic feet. Plantar ulceration may also be initiated by deep pressure necrosis due to forces of thrust and shear which traumatize the soft tissue lying between the skin of the sole and the rigid bones of the foot.

\section{Causes of recurrence of plantar ulceration}

In describing the basic aetiopathology of recurrent plantar ulceration, Price (1959) has shown that trophic ulcerations occur in anaesthetic feet along the areas of maximum mechanical strain or high pressure during walking. That mechanical strain is an important factor is evident from the fact that plantar ulcer occurs along the "walking roll", and it heals as soon as the "walking cycle" of the foot is broken. Rest in bed, application of a posterior slab, or a plaster of Paris walking cast all result in interruption of the walking cycle and 
healing of the ulcer. In fact, according to published reports, the majority of ulcers seem to heal with remarkable regularity despite a wide variety of methods of treatment (Price, 1961). The problem in the large majority of cases thus seems to be not one of initial healing of the ulcer but of preventing its recurrence.

\section{Principles in the prevention of plantar ulceration}

In order to prevent plantar ulceration, we have to offer protection against external trauma as well as to modify the mechanical stresses at each phase of the normal gait.

While external trauma can be easily avoided by wearing most types of conventional footwear, it is important to eliminate trauma due to the footwear itself when it is being used by patients with anaesthetic feet. Obvious causes of trauma, such as the nails with which the straps are fixed, the sharp edges of an ill-fitting strap or a heel counter, must be avoided. Friction between the skin and the leather strap should also be minimized. Footwear that squeezes the foot tightly around the metatarsal heads, thus increasing the pressure under them, should be avoided.

Mechanical stress during normal gait can be reduced by footwear that prevents concentration of the body weight in localized areas of the "walking roll" during each step. In a rigid soled rocker-shoe, reduction of peak pressure under the forefoot during the kick-off phase is achieved by adding a heel and a rocker under the sole. The addition of a moulded insole results in uniform distribution of the pressure throughout the sole, through all the phases of the walking cycle. However, a large number of patients are unwilling to wear such cumbersome footwear, which they find difficult to manage over rough terrain or on the narrow footpaths that divide wet fields. The time, expertise, and expense incurred in making individual footwear for each patient makes it also impracticable for general use in the management of a large number of patients with anaesthetic feet. Though such special footwear may be essential for the badly scarred and shortened foot, the majority of anaesthetic feet with minimal or morlerate scarring do not need such extreme measures. However, the main principle on which the rocker shoe is designed is sound and hence should be adopted in the development of suitable footwear. Thus design of the footwear should be such as to enable reduction of peak pressure along the metatarsal heads by preventing excessive heel-lift and hyperextension at the metatarso-phalangeal joints.

Taking into consideration the various factors responsible for plantar ulceration, we have been able to develop a sandal (chappal) using microcellular rubber and a carefully designed upper, called the "Y"-strap microcellular rubber chappal, the features and effectiveness of which are described and discussed below.

\section{MICROCELLULAR RUBBER}

Microcellular rubber known technically as "microporous compound", is basically the same compound as that used in the "Hawaii chappals", except for certain changes in the physical properties to suit the particular requirements of the anaesthetic feet. The finished microporous compound has millions of individually enclosed tiny air spaces with thin walls closely packed together. The strength and resilience needed to sustain such a structure are obtained by the use of suitable chemicals and by achieving the optimum "cure" for the

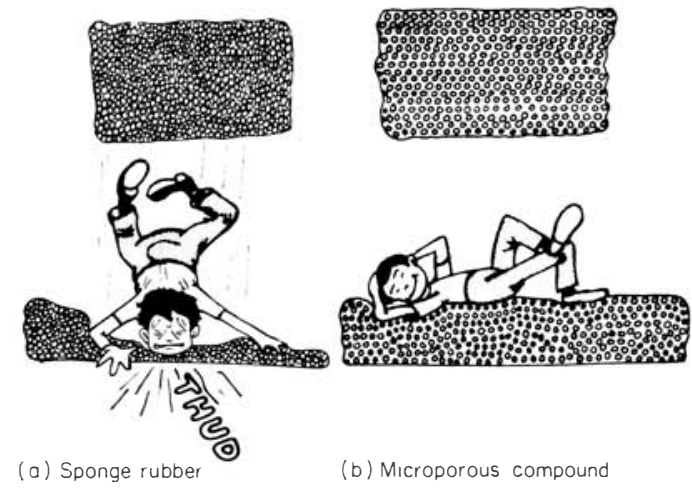

FIG. 1

(a) The inter-communicating spaces of the sponge rubber results in emptying of the spaces and total compression of the sponge on pressure.

(b) The individually enclosed air spaces in the microporous compound gives it the elasticity and buoyancy which allows the foot to "float" on it. 


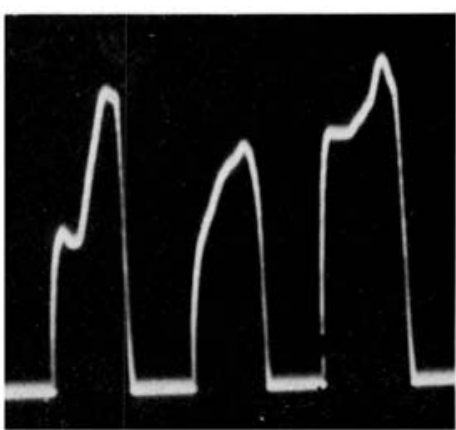

(a)

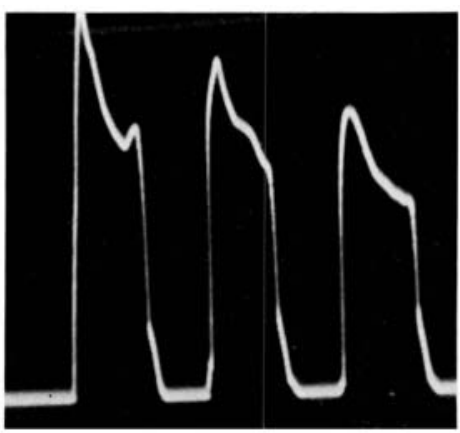

(b)

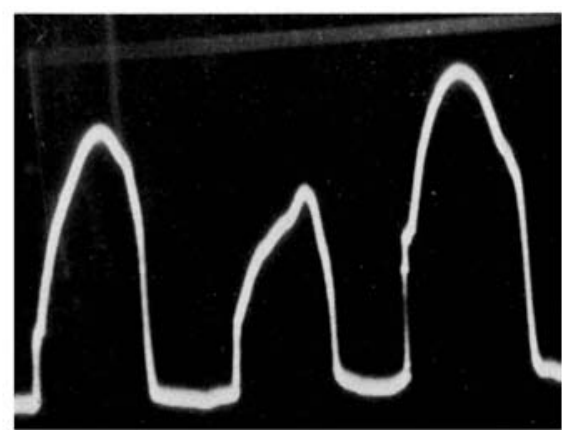

(c)

Fra. 2

Tracing on cathode ray oscillograph from a pressure senstive disc applied under first metatarsal head while walking. (a) Pressure tracing during 3 successive steps taken on 20 and $15^{\circ} \mathrm{A}$ microcellular rubber and on the floor, (b) Pressure tracing of 3 successive steps taken on the floor, 15 and $10^{\circ} \mathrm{A}$ microcellular rubber, (c) Pressure tracing of 3 successive steps taken on $3 \mathrm{~mm}$ thick microcellular rubber, ${ }_{4}^{3} \mathrm{in}$. thick mircocellular rubber and on the floor. Note that no significant reduction in the peak pressure occurs in both $20^{\circ} \mathrm{A}$ microcellular rubber and $3 \mathrm{~mm}$ thick microcellular rubber.

rubber. The final product is soft and spongy, having an elastic buoyancy which enables the foot to "float" (Fig. 1). It is interesting to note that the subcutaneous fat of the normal sole is itself of a similar structure, each fat globule being enclosed in individual fibrous tissue compartments which impart elasticity and buoyance to the soft tissue pad next to the sole.

The unit of measurement of the resilience or compressibility of the rubber is the "shore A". The normal soles of people who habitually walk on bare feet measure from 15 to $20^{\circ} \mathrm{A}$, and in those who walk with closed shoes from 10 to $20^{\circ} \mathrm{A}$ (personal observation). Most of the commercially available rubber measures more than $20^{\circ} \mathrm{A}$ and is too hard to provide adequate protection to anaesthetic feet. We have found that a soft, recently healed scar at the site of plantar ulceration, where the subcutaneous fat is destroyed, measures 20 to $50^{\circ} \mathrm{A}$ (personal observation, unpublished).

The microcellular rubber sole forms a protective, soft cushion under the anaesthetic foot, capable of effectively reducing peak pressures along the "walking roll". Its compressibility when combined with adequate thickness provides an instant mould under the walking foot. The high pressure points sink $\frac{1}{2}$ in. $(1.25 \mathrm{~cm})$ into the microcellular rubber, thereby increasing the available area of weightbearing surface. This results in a reduction of the peak pressure per unit area, due to distribution of the pressure over a wider surface. In addition, when the foot sustains a heavy impact, as in jumping, the springiness of the rubber slows down the rate of deceleration and thus reduces the impact (Brand, 1966). It is important to ensure that the thickness and the softness are balanced in such a way that the rubber does not get totally compressed and become rigid under high-pressure areas at times of peak pressure; the remaining buoyancy of the rubber protects the soft tissue that lies between the unyielding floor and the rigid bone. A microcellular rubber sole of 10 to $15^{\circ} \mathrm{A}$ to $\frac{3}{4}$ in. $(2 \mathrm{~cm})$ in thickness is found to fulfil the above criteria (Fig. 2 (a) to $(\mathrm{c}))$.

To maintain its spongy structure even after prolonged use, the microcellular rubber needs (a) abrasive resistance, (b) elastic recoil, and (c) tackiness.

\section{(a) Abrasive resistance}

Under high-pressure points, shearing force is added when the foot slips forward during acceleration and deceleration. The surface layer of the microcellular-rubber insole is thus subjected to the constant stress of friction. It is 


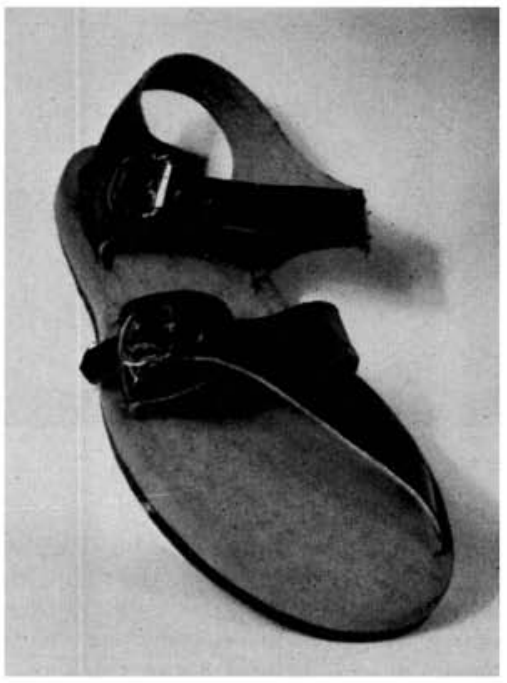

FIG. 3

The "Y"-strap microcellular rubber chappal.

important that the rubber should not wear out in this area where thickness and buoyancy are especially required.

\section{(b) Elastic recoil}

When the septa between the air spaces in the microcellular rubber are weak and lacking in resilience, they break down or become distorted when subjected to pressure. The softness and elastic recoil are then lost and the rubber gets compressed and hard under the foot. The softness and springiness of the microcellularrubber compound are essential for reducing the compressive force on the soft tissue under the high-pressure areas and also to permit of instant moulding of the foot, which will then provide a larger area of the sole for weight-bearing.

\section{(c) Trackiness}

Ability to withstand tearing force is described as "tackiness". When this is lost, the rubber tends to tear easily wherever it is stitched or at the point of insertion of the straps. Occasionally, it may even split across the sole in the forefoot area where it has to bend frequently.

The above 3 properties depend on the quality of the materials and chemicals used and on the process of mixing and curing. A well-finished microcellular-rubber compound should be able to withstand constant wear for 18 to 24 months without losing its essential physical properties.

\section{EFFECTIVENESS OF " $Y$ "-STRAP MICROCELLULAR RUBBER CHAPPAL IN THE PREVENTION OF PLANTAR ULCERATION}

In the "Y"-strap chappal (Fig. 3) the microcellular-rubber is lined underneath with a material that cannot be easily pierced by thorns or nails. Cow-hide, split car tyres, or a custom made vulcanized rubber sole may all be used for this purpose. No nail or metal is used to fix the upper to the sole. The strap across the forefoot is placed at the level of the mid-shaft of the metatarsals, thus avoiding "squeezing" the metatarsal heads. The straps are designed to fit the contour of the foot without the edges pressing abnormally, and are lined inside with "khaki" cloth so that the friction during walking is taken up partly by the movement between the cloth and the leather instead of between the skin and the leather. All straps in the sandal should have adjustable buckles so that when a foot is swollen or bandaged the straps may be readjusted to allow for the extra width needed around the foot (Fig. 4). Failure to provide for this will result in a new area of concentrated pressure which may initiate fresh ulceration.

The shearing force during acceleration and deceleration is markedly reduced by the

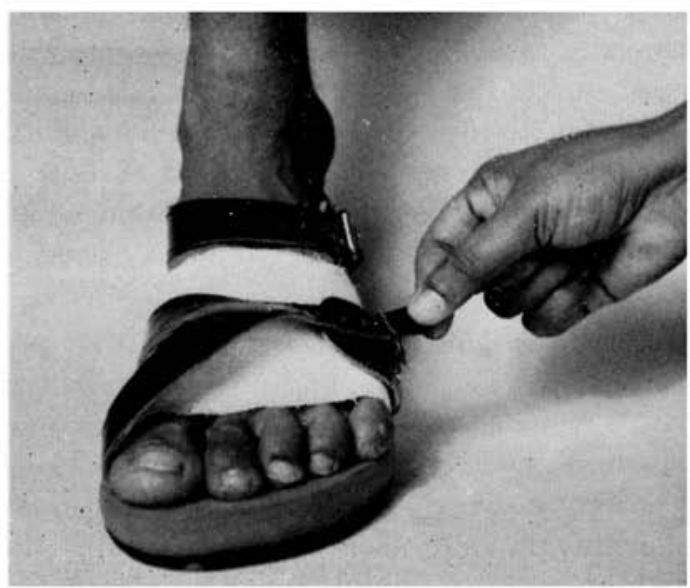

FIG. 4 


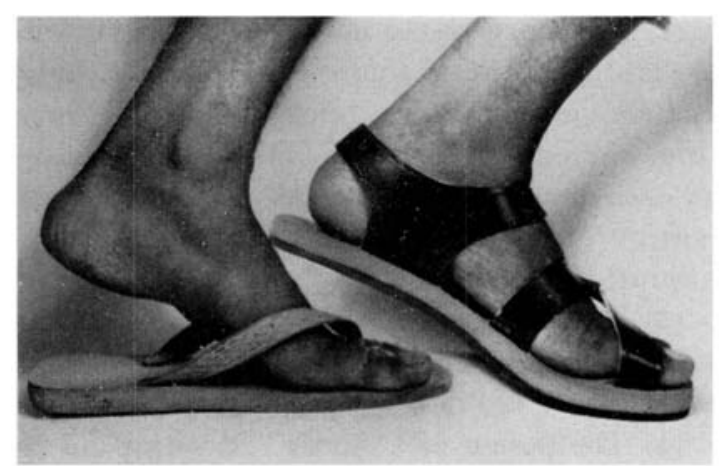

FIG. 5

sponginess of the microcellular rubber and also by the fact that as the foot slides forward in the footwear, the rubber yields and remoulds, thus eliminating the resistance of the "floor".

The principles used in the design of the rocker shoe can also be adapted to the microcellularrubber chappal. Thus heel-lift and hyperextension at the metatarso-phalangeal joints during the "kick-off" phase are reduced by adding a back strap. When there is no back strap, the heel is raised awayfrom the footwear with a resultant reduction in the weight-bearing area and concentration of the weight of the body in the forefoot area (Fig. 5). In addition, the front strap of the "Y"-strap chappal is placed proximally, obliquely across the middle of the shaft of the metatarsals and not across the metatarsal heads. Thus the forefoot is held flat in the footwear at the mid-foot level, limiting hyperextension at the metatarsophalangeal joints. An additional "limb" to the front strap helps to provide further support for the front part of the chappal.

The disadvantage inherent in a rigidly moulded insole is its inability to adapt to the altering contour and movement of the foot during walking. This disadvantage is effectively eliminated by the use of microcellular rubber, which not only forms an instant mould but also alters its contour to fit every change in the foot; one may call it a "mobile mould".

In our experience, this "Y"-strap microcellular-rubber chappal has given satisfactory results in preventing the initiation and re- currence of ulceration in the majority of patients with anaesthetic feet which are minimally or moderately scarred. However, such footwear does not withstand the rigours of wet farming and heavy field work. A simple "Y"-strap chappal is also not adequate for severely deformed feet which are mechanically unsuitable for normal weight-bearing. Recurrent plantar ulceration may appear in severely shortened and extensively scarred feet which are incapable of withstanding even the minimal stress of normal walking. Such problem feet need special adaptation to reduce the stress below the level that is "critical" to the particular foot. Thus, modifications that help to distribute pressure to the maximum available area and eliminate peak pressure during the walking cycle should be made use of. A moulded shoe that has a soft microcellular-rubber lining and a rocker is often adequate (Fig. 6 (c) and (d)). Very badly scarred feet which are totally incapable of even minimal weight-bearing may be fitted with a patellar-tendon-bearing prosthesis in which the weight is taken around the knee and the foot "floats" inside the prosthesis allowing easy mobility and stability.

High pressure areas across the metatarsal heads or forefoot may be relieved by a type of footwear which incorporates a metatarsal bar and a heel counter (Fig. 6 (b)). The heel counter is important to ensure that the metatarsal bar lies well behind the high pressure area; lack
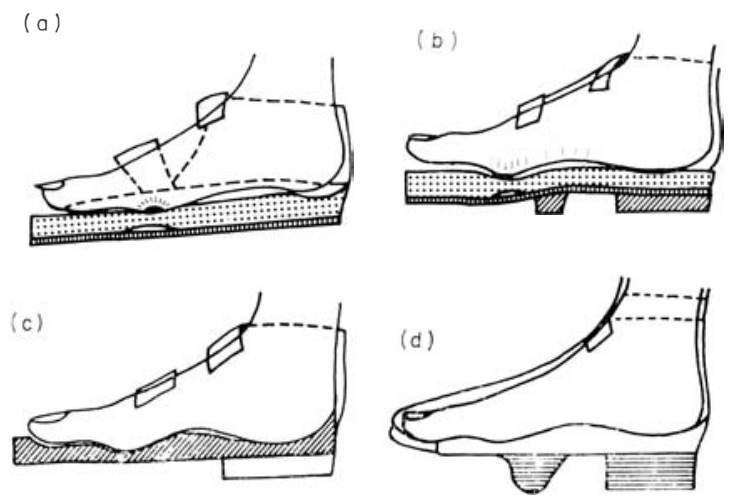

Fig. 6

(a) Scooped out microcellular rubber; (b) metarsal bar; (c) moulded insole; (d) rocker shoe. 


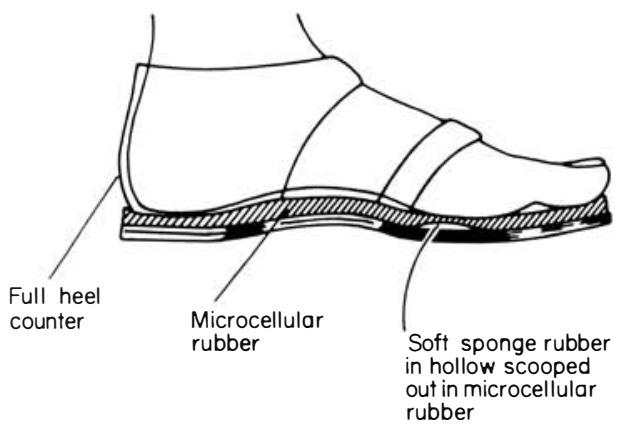

FIG. 7

of a heel counter allows the foot to glide backwards in the shoe, resulting in the metatarsal bar lying right under the high-pressure area.

A small localized high-pressure area may be relieved by partial scooping of the rubber from underneath the sole to give a smooth concave depression on the top (Fig. 7). Scooping on the upper surface leaves a rough edge and as a result of the friction the ulcer may "creep" forward. Again a heel counter to maintain the foot in position is essential.

In our experience we have found that a hard avascular scar that is liable to recurrent ulceration improves in quality when protected from excessive stress for a period of time. Often a more complicated type of footwear may be replaced by standard footwear after a period of a year or so when the texture of the soft tissue has improved.

A large majority of anaesthetic feet are capable of remaining ulcer-free when fitted with a standard "Y" -strap chappal. If patients with anaesthetic feet, with or without plantar ulceration, can be persuaded to use these microcellular-rubber chappals regularly, then we may be able successfully to eliminate a major disability in leprosy patients.

\section{SUMMARY}

(1) Plantar ulceration causing major disability in nearly $20 \%$ of leprosy patients will continue to persist in the absence of suitable protective footwear. The management of plantar ulceration should be in terms of long-range care rather than of immediate results, since we are dealing with permanently anaesthetic feet.
(2) The cause of the initiation and recurrence of plantar ulceration and the principles involved in their prevention are briefly indicated. Apart from the external trauma, mechanical stresses at each phase of the normal gait play an important role in the causation of plantar ulceration.

(3) The salient qualities of microcelluar rubber, known technically as "microporous compound", are described in detail.

(4) The design of a simple "Y" -strap microcellular-rubber chappal is presented and its effectiveness discussed in relation to the various grades of severity of plantar ulceration.

(5) It is maintained that if plantar ulceration is detected early and the type of chappal described is used regularly, the problem of plantar ulceration can be successfully minimized or even eliminated.

\section{ACKNOWLEDGEMENTS}

I am grateful to the Director and staff of the Madras Rubber Factory without whose help and co-operation we would not have been able to experiment and manufacture microcellular rubber for the use of a large number of patients all over the world.

My thanks are also due to Mr. Doorvasalu who has supervised the manufacture of the various types of microcellular-rubber chappals; and to Mr. Fred Morenas, Miss Indira and to Mr. S. Philip for secretarial help.

I am indebted to the Leprosy Mission, London, and to the American Leprosy Mission, New York, for financial support and encouragement.

\section{REFERENCES}

BRAND, P. W. (1966). Insensitive Feet. A Practical Handbook on Foot Problems in Leprosy. The Leprosy Mission, 7 Bloomsbury Square, London, W.C.I. Leorosy Centre, Polambakkam. Report of Activities for 1955-1962. Polambakkam P.()., Madurantakam Taluk, Madras State, India.

NOORDEEN, S. K. and SRINIVASAN, H. (1966). Epidemiology of disability in leprosy. A general study of disability among male patients above 15 years of age. Int. .J. Lepr. 34, 159.

Price, E. W. (1959). Studies in plantar ulcer in leprosy. Lepr. Rev. 30, 98, 180, 242.

PRICE, E. W. (1961). Plantar ulcer in leprosy. A review of the literature. Lepr. Rev. 32, 108. 